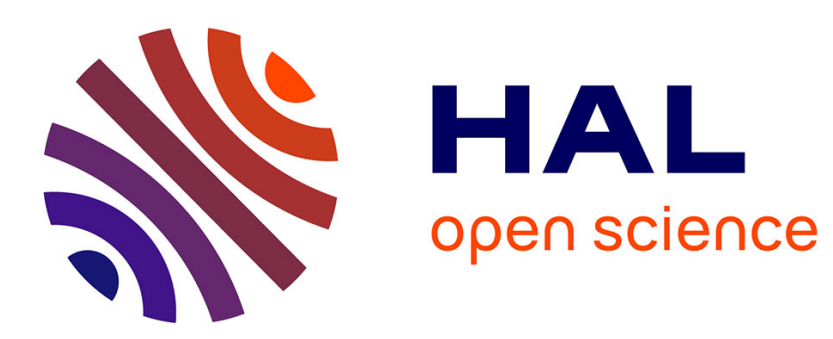

\title{
Gender Inequality, Endogenous Cultural Norms and Economic Development
}

Victor Hiller

\section{To cite this version:}

Victor Hiller. Gender Inequality, Endogenous Cultural Norms and Economic Development. 2008. halshs-00344793

\section{HAL Id: halshs-00344793 \\ https://shs.hal.science/halshs-00344793}

Submitted on 5 Dec 2008

HAL is a multi-disciplinary open access archive for the deposit and dissemination of scientific research documents, whether they are published or not. The documents may come from teaching and research institutions in France or abroad, or from public or private research centers.
L'archive ouverte pluridisciplinaire HAL, est destinée au dépôt et à la diffusion de documents scientifiques de niveau recherche, publiés ou non, émanant des établissements d'enseignement et de recherche français ou étrangers, des laboratoires publics ou privés. 


\section{Documents de Travail du Centre d'Economie de la Sorbonne}

C

E

$\mathrm{S}$

W

0

1

k

i

$\mathrm{P}$

a

$\mathrm{p}$

e

1

$\mathrm{S}$

CENTRE NATIONAL

DE LA RECHERCHE

SCIENTIFIQUE

Maison des Sciences Économiques, 106-112 boulevard de L'Hôpital, 75647 Paris Cedex 13

http://ces.univ-paris1.fr/cesdp/CES-docs.htm

ISSN : 1955-611X

2008.75
Gender Inequality, Endogenous Cultural Norms and

Economic Development

Victor HILLER 


\title{
Gender Inequality, Endogenous Cultural Norms and Economic Development
}

\author{
Victor HILLER* \\ Paris School of Economics \\ Université Paris I - Panthéon Sorbonne
}

November 24, 2008

*Centre d'Economie de la Sorbonne, 106-112 Boulevard de l'Hôpital 75013 Paris, France. <hiller@univ-paris1.fr> 


\begin{abstract}
This research focuses on the role played by cultural norms in the long run persistence of gender inequalities. Cultural norms about gender roles are considered to be endogenous and can generate gender inequality and low development traps. Indeed, when the gender gap is internalized, it leads to inegalitarian views about gender roles. Due to these inegalitarian beliefs, boys receive more education and the initial gender gap is reinforced. The existence of gender inequality traps is pointed out by the World Bank as a major obstacle for economic development (WDR 2006). The present article allows for a better understanding of the persistence of such traps and the means to escape.
\end{abstract}

\title{
Résumé
}

Cet article s'intéresse au rôle joué par les normes culturelles dans le phénomène de persistance des inégalités hommes-femmes. Les normes culturelles régissants le rôle respectif des hommes et des femmes sont supposées endogénes et peuvent générer l'émergence de trappes à inégalité et à pauvreté. En effet, les inégalités entre genres sont internalisées par les agents et conduisent à une vision inégalitaire du rôle que doit jouer chacun au sein de la société. A cause de ces croyances inégalitaires, les garçons reçoivent une éducation supérieur à celle reçue par les filles et l'inégalité initiale est renforcée. L'existence de trappes à inégalité entre hommes et femmes est mis en avant par la Banque Mondiale comme un des obstacle majeur au dévéloppement économique (WDR 2006). Cet article permet de mieu comprendre la persistence de ce type de trappe et les moyens d'en sortir.

JEL Codes: J16, O15, Z10.

Keywords: Gender Equality, Endogenous Cultural Norms, Economics Development, Inequality Traps. 


\section{Introduction}

This article deals with the role played by endogenous cultural norms about gender roles in the persistence of gender inequalities and the economic development. It highlights a two way causality between norms and educational gender gap. On the one hand, gender differences in education determine the women participation to the labor market, which affects individuals views about their role within the society. For instance, a low level of participation induces a widespread belief that women have a comparative advantage in housework rather than on the labor market. On the other hand, due to this inegalitarian belief, parents would value less girls education compared to the education of boys. It results in a joint evolution of both the level of human capital in the economy and the gender role attitudes.

In an economy initially poor (where neither men nor women receive education), task sharing between men and women is determined by the relative physical srength of each spouse. Men being endowed with more strength, their labor supply is higher. Consequently, gender role attitudes favor the boys. Since boys are initially favored, as the economy develops, men are the first to receive education. Men's education allows for further developments of the economy through the accumulation of human capital. However, this accumulation has a perverse effect. Indeed, it increases the productivity gap between men and women, which leads to a decrease of the relative labor supply of women and to less egalitarian views about gender roles. Consequently, a country can be trapped in a long-run situation in which only men are educated. Conversely, if the accumulation of mens' education leads to a level of development which allows for the education of girls, the economy converges towards a high-output equilibrium characterized by a relative equality between men and women. Indeed, a rise in women's education implies a decrease of the relative productivity of men. As a consequence, the relative labor supply of women increases and views about gender roles become less traditional. ${ }^{1}$

The World Development Report 2006 documents the existence of inequality traps. Among them, the gender inequality trap has a central place. Moreover, the report points out the role of cultural norms in the perpetuation of

${ }^{1}$ I use here the terminology of Farre and Vella (2007), the term traditional reflects the view that women should specialize in home production and men in market. 
gender differences and then, in the persistence of this kind of traps. ${ }^{2}$ The model presented below, allows to take into account the importance of social norms in the persistence of unequal opportunities between genders. The fact that boys receive more education than girls is not an efficient choice but results from the weight of inegalitarian social norms. In turn, these choices tend to increase the gender inequalities on the labor market and then to reinforce the inegalitarian norms.

The proposed theory also suggests that gender inequalities may impede the economic development. The negative relationship between gender inequality and development or economic growth has been highlighted by several empirical studies. Controlling for potential endogeneities (the level of development affects the level of gender inequality), Klasen (1999) and Dollar and Gatti (1999) find that gender inequalities in education have a direct and negative impact on economic growth. Knowles et al. (2002) estimate a neoclassical growth model including male and female education. They also conclude that the educational gender gap is a barrier to the economic development.

Finally, the present model enables to replicate the U-shaped relationship between female labor supply and economic development. This relationship has been highlighted both in cross-country analysis ${ }^{3}$ and on longitudinal data. ${ }^{4}$ However, few theoretical works give foundations to these findings. ${ }^{5}$ In the present paper, the less developed countries are characterized by no education for both men and women, then the sole difference in labor market opportunities comes from physical strength or discrimination towards women:

${ }^{2}$ WDR 2006, p.51: "Gender inequity is the archetypical inequality trap. Most societies have norms that preserve the prevalent social order, delineating different roles and spheres of influence for men and women. The male sphere is typically outside the home in market work [...] The female sphere is usually inside the home - looking after household work, rearing children, and contributing to the stability of the household."

${ }^{3}$ see Durand (1975), Goldin (1995), Cagatay and Olzer (1995) or Mammen and Paxson (2000).

${ }^{4}$ see Goldin (1995) for the United State for the period since 1790 or Mammen and Paxson (2000) for evidence from Thailand and India.

${ }^{5}$ Galor and Weil (1996) propose two extensions of their basic model in order to obtain this relationship. The first one focuses on the role of the high child mortality at low levels of development; the second one considers the existence of a non-modern production sector requiring no capital. In both cases, the initial fall of women labor participation comes with a fertility rise. 
It results in a substantial participation of women to the labor market. During early stages of development, only mens' education increases. Then, the productivity gap between men and women rises and the labor supply of women falls. Then, if the economy reaches a sufficient level of development, women are also educated and the gender gap in labor productivity is progressively filled. It corresponds to the rising portion of the U-curve.

The two following sections deal with the theoretical literature related to the present article and the empirical foundations associated with the law of evolution of gender roles.

\section{Related literature}

The present article aims at building a bridge between a literature focusing on the relationship gender inequalities - economic development; and a literaure which consider cultural norms about gender roles as endogenous.

The relationship between gender gap and economic development has been investigated in overlapping generations models with endogenous fertility. In their seminal work, Galor and Weil (1996) assume that men have greater physical strength than women while men and women have the same amount of mental input. The economy is initially in a Malthusian trap, characterized by a high fertility and a low development level. Due to the process of capital accumulation, returns of mental input increase while returns of physical strength remain constant. Consequently, the relative productivity of women rises which generates the fertility transition. I depart from this framework, focusing on the accumulation of human capital rather than physical capital. Moreover, the present model gives a role to the culture in the relationship between the gender gap and economic development.

The article of Lagerlöf (2003) is more closely related to my own. The author focuses on the accumulation of human capital and explains the different endowments in education of men and women by cultural factors. Parents invest in education in order to maximize the total income of the future household into which their children enter. A coordination game between families arises: if all families favor the education of boys, the optimal choice is to act the same. It results in a continuum of Nash equilibria which determine the share of education between girls and boys. In this framework, cultural norms allow for the coordination of all families on one equilibrium. Taking 
historical illustrations, the author assumes that cultural norms favor initially boys, but progressively evolve towards less traditional views about gender roles. Then, the economy re-coordinates at each date on a more egalitarian Nash equilibrium. This evolution enables to reproduce the long run pattern of demographic and economic history in Europe. My approach differs from Lagerlöf's one by considering the process of cultural evolution as endogenous. It allows to generate gender inequalities traps which are absent from the Lagerlöf's model. ${ }^{6}$

Another recent paper, from de la Croix and Vander Donckt (2008), considers the role of social norms in a model in which fertility, gender gap and bargaining power within the household are endogenized. Social norms represent the part of bargaining power which is not endogenously determined. It captures the societal and institutional propensity of a country towards gender equality. In this framework, social norms are exogenous and their evolution do not enable to escape from the Malthusian trap.

The major difference of my own approach with respect to this literature is the absence of endogenous fertility behaviors. This aspect is discussed in section 8. The model assumes that individuals spent time in order to produce a domestic good, men and women having the same abilities in the production of this good. This formulation simplifies the analysis and avoids the complete specialization of tasks within the household. It allows to endogenize the gender role attitudes in a simple and relevant way. Moreover, the uncomplete specialization complies with empirical observations (see de la Rica et al. (2008) for European data).

A second part of the literature related to this article focuses on the endogeneity of gender roles. Escriche et al. (2004) assume that women differ by their views about gender role. These different opinions correspond to various preferences: women have either job-priority or family-priority preferences. The process of preferences evolution is in line with the model of cultural transmission of Bisin and Verdier (2001). The policy adopted by the firms (discriminatory or not) depends on their expectations about the proportion of family-priority women. In turn, the parental incentives to transmit familypriority preferences increase with the level of discrimination set by the firm.

${ }^{6}$ I also adopt an alternative definition of culture. Lagerlöf (2003) considers cultural norms as a mean to coordinate on one equilibrium, in my model, cultural norms directly affect preferences. 
It results in the existence of two possible long run equilibria: the discriminatory and the non-discriminatory one. The discriminatory (respectively non-discriminatory) equilibrium is characterized by a high (low) proportion of family-priority women and a discriminatory (non-discriminatory) firms' policy. The present paper also highlights the complementarity between discrimination on the labor market and more traditional gender role attitudes. As previously pointed out, it could then induce multiple equilibria.

Fernandez et al. (2004) consider cultural norms as a parameter of men's utility function: men suffer a potential disutility when their wife works. They also assume that the proportion of men having traditional views about gender roles (i.e. suffering a disutility if their wife works) evolves endogenously. More precisely, a man's disutility of a working wife depends on whether his mother worked outside the home. In this framework, an exogenous positive shock on the women labor market participation (as the advent of the World War II), increasing the proportion of working mothers, induces the diffusion of modern gender role attitudes. In line with this work, I also assume that the observation of women labor supply behaviors shape beliefs about gender role within the society.

In this article, the relationship between gender role attitudes and labor supply is integrated in an OLG model. It enables to highlight the consequences of the endogeneization of cultural norms on economic development.

\section{On the definition and evolution of gender role attitudes}

A growing literature provides evidences relating culture and economic decisions (see Fernandez (2006) for a brief overview). A part of this literature focuses on the role of cultural norms about gender roles. Vella (1994), Farré and Vella (2007), Fernandez (2007) and Fernandez and Fogli (2007) conclude that these norms have quantitative and significant effects on women's labor force participation decisions.

In the present article, the relationship between culture and labor market outcome is indirect. Cultural norms affect educational choices of parents for their children which, in turn, impact children's participation decisions. Few empirical works investigate the link between gender role attitudes 
and investment in human capital. On Australian data, Vella (1994) finds that traditional beliefs about gender roles reduce human capital investment for girls. Concerning developing countries, cultural factors, as patriarchal norms are commonly cited in sociological studies, as a reason for girls' limited school participation (see for instance Greenhalgh (1985), Davison and Kanyuka (1992) or Hyde (1993)).

Cultural norms about gender role are assumed to have two components: a slow-moving component (exogenous in the model) and a fast-moving component (endogenous in the model). The distinction between slow-moving and fast moving components of culture is made by Guiso et al. (2006). It captures the fact that part of cultural norms in a society is persistent and not much affected by agents decisions. It is typically the case of religious norms. Using the World Value Survey, Guiso et al. (2003) show that religion is positively related with traditional views about gender roles. ${ }^{7}$

The fast moving component of gender roles attitudes is transmitted across generations but is also affected by the observation of the relative labor supply behaviors of men and women. Fernandez et al. (2004), Farré and Vella (2007), Fernandez (2007) and Fernandez and Fogli (2007) provide evidences on the intergenerational transmission of cultural attitudes regarding the role of women. Concerning the impact of women labor supply on gender role attitudes, Farré and Vella (2007), Fernandez (2007) and Kawaguchi and Miyazaki (2008) argue that wives of men whose mother worked, are themselves significantly more likely to work. One interpretation of this finding is the following: men growing up with a working mother have acquired a more modern view about gender roles.

Again, the mechanisms at play differ in the model. It is the observation of the "average behavior" in the whole population which influences opinions about gender roles. This assumption is in line with the theories of statistical discrimination (pioneering by Phelps (1972) and Arrow (1973) works): A relatively low participation of women on the labor market leads to the belief that they have a comparative advantage in housework rather than in market

\footnotetext{
${ }^{7}$ Authors measure gender role attitudes thanks to various questions on the role of women within the society. Among them, respondents have to give their level of agreement with the following statement: "A university education is more important for a boy than for a girl". This question is closely related with our definition of gender roles since it deals with the relative weight given by parent to the education of boys and girls. Authors conclude that, to be actively religious rise the probability to agree with this statement.
} 
activities. My mechanism of preferences formation also complies with the litterature highlighting the role of social norms and habit formation on individual attitudes in the labor market (Blomquist (1993), Lindbeck (1995), Lindbeck et al. (1999), Farria and Leon-Ledesma (2004), Jakee and GuangZen (2005) or Bonatti (2008)). Indeed, in this litterature, individual preferences are shaped by average behaviors in the whole society or in reference groups. Woittiez and Kapteyn (1998) provide evidences on the positive effect of reference group mean of participation rate on the female labor supply.

\section{The model}

\subsection{Basic structure}

Consider a two-sex overlapping generations economy. Each individual lives for two periods. During the childhood, men and women are identical and receive education. During the adulthood, both men and women work, either at home or on the labor market. They differ in terms of their ability to earn wages on the labor market. In line with Galor and Weil (1996), I assume that men are endowed with physical strength and mental input while women are only endowed with mental input. ${ }^{8}$ Moreover, the amount of mental input of each individual depends on her/his level of education.

This level of education is chosen by parents. Two parents (one man and one woman) compose a couple and each couple has two children (one boy and one girl). Women and men have the same preferences such that couples are taken to have a joint consumption and a joint utility. In addition, since there is no heterogeneity within each generation, the features of matching process do not matter: men and women are randomly matched.

\subsection{Production}

Each individual is endowed with one unit of time shared between housework and work on the labor market. In line with Zick et al. (2008), housework includes meal preparation, clean up, laundry, shopping, maintenance

${ }^{8}$ This assumption justifies the initial differences of gender roles. As discussed in section 8 , it can be relaxed assuming, for instance, that women are discriminated on the labor market. 
of residence, child care, gardening or even bookkeeping related to household management. In this model, all these activities are represented by the production of a composite good, namely a domestic good. The quantity of time devoted to housework by an individual $i$ at date $t$, is denoted $l_{t}^{i}$, with $i \in\{f, m\}$. Moreover, the housework time exhibits decreasing returns: a quantity of time $l_{t}^{i}$ implies the production of $\left(l_{t}^{i}\right)^{\gamma}$ units of domestic good, $\gamma \in(0,1)$. This assumption captures fatigue effects associated with the production of the domestic good. It follows that, the total amount of domestic good produced by a couple at date $t$ (denoted $D_{t}$ ) equals:

$$
D_{t}=\left(l_{t}^{f}\right)^{\gamma}+\left(l_{t}^{m}\right)^{\gamma}
$$

This implies that men and women produce the same amount of domestic good providing an equal quantity of time. ${ }^{9}$

When individuals do not work at home, they offer remaining time (1 $l_{t}^{i}$ ) on the labor market in order to produce a manufactured good. Labor is the only input used in the production of this good. It is composed of both physical strength and mental input. Strength and mental input are assumed to be perfect subsitutes such that, the wage per unit of labor, i.e. the productivity of one unit of labor, is equal to:

$$
w_{t}^{i}=s^{i} b+h\left(e_{t}^{i}\right)
$$

with $s^{i}$ the endowment of physical labor for the individual $i \in\{m, f\}$ and $b$ the productivity of one unit of physical strength. To simplify, it is assumed that women have no physical strength while men have a positive amount of it. Formally, it comes:

$$
s^{i}=\left\{\begin{array}{lll}
0 & \text { if } & i=f \\
1 & \text { if } & i=m
\end{array}\right.
$$

$h\left(e_{t}^{i}\right)$ represents the level of mental input (human capital) of an individual $i$. It is positively related to the level of education $\left(e_{t}^{i}\right)$ received by her $/ \mathrm{him}$ during the childhood. Moreover, it is assumed that $h(0)>0$. It implies that each individual is endowed with a minimum amount of mental input

\footnotetext{
${ }^{9}$ The production function of household good proposed by Fernandez et al. (2004) displays the same properties that my own. Consider a CES production function (as in Albanesi and Olivetti $(2006,2007))$ does not affect our results.
} 
even if she/he did not receive any education (see Moav (2005) for further discussions). ${ }^{10}$

\subsection{Preferences and budget constraint}

The preferences of a couple of generation $t$ are defined over consumption of domestic and manufactured goods (respectively denoted $D_{t}$ and $C_{t}$ ) as well as over the human capital of their children. Preferences are represented by the following utility function:

$$
U_{t}=\mu \ln C_{t}+(1-\mu) \ln D_{t}+\beta\left[\theta_{t} \ln \left(h\left(e_{t+1}^{f}\right)\right)+\ln \left(h\left(e_{t+1}^{m}\right)\right)\right]
$$

The parameter $\theta_{t}$ denotes the relative weight given to education of the daughter compared to the education of the son in parental preferences. $\theta_{t}$ is regarded as a measure of parental views about gender roles. Indeed, if parents think that women are more productive at home, they will give less weight to the education of girls compared to the education of boys and $\theta_{t}<1$. $\theta_{t}$ is considered as given when parents decide on their choices of education. However, this parameter is endogenous (see section 4.7) and its evolution is partly determined by the female labor supply: higher is the women' participation, weaker is the belief that women have a comparative advantage in housework. To comply with empirical regularity that women had never been more educated than men along the process of development, the study focuses on the case $\theta_{0}<1$. It implies that parents initially favor boys. As it will be shown, under this condition $\theta_{t} \leq 1$ for all date $t$. Thus, the analysis is restricted to the case:

$$
\theta_{t} \leq 1
$$

implying $e_{t}^{m} \geq e_{t}^{f}$. However, the case $\theta_{t} \geq 1$ could also be considered.

The couple's earnings are used to consume the manufactured good and to educate children. These earnings equal the wages received on the labor market. Hence, through (2) and (3), the budget constraint of the couple is:

$$
\left(1-l_{t}^{f}\right) h\left(e_{t}^{f}\right)+\left(1-l_{t}^{m}\right)\left(h\left(e_{t}^{m}\right)+b\right)=C_{t}+\tau\left[e_{t+1}^{f}+e_{t+1}^{m}\right]
$$

\footnotetext{
${ }^{10}$ Identical results are obtained assuming that parents face a hierarchy of need, children's education coming after consumption (see Strulick (2003)).
} 
with $\tau$ the relative cost of one unit of education and $e_{t+1}^{i}$ the quantity of education chosen for a child $i$.

The representative couple maximizes its utility (4) by choosing $C_{t}, D_{t}, l_{t}^{f}$, $l_{t}^{m}, e_{t+1}^{f}$ and $e_{t+1}^{m}$ subject to the budget constraint (6) and the technological constraint on the domestic production (1).

\subsection{Optimization}

The optimization, with respect to the labor supply of men and women $\left(l_{t}^{f}\right.$ and $l_{t}^{m}$ ), implies that:

$$
\begin{gathered}
\frac{\mu h\left(e_{t}^{f}\right)}{\gamma(1-\mu) C_{t}}=\frac{\left(l_{t}^{f}\right)^{\gamma-1}}{\left(l_{t}^{f}\right)^{\gamma}+\left(l_{t}^{m}\right)^{\gamma}} \\
\frac{\mu\left(h\left(e_{t}^{m}\right)+b\right)}{\gamma(1-\mu) C_{t}} \geq \frac{\left(l_{t}^{m}\right)^{\gamma-1}}{\left(l_{t}^{f}\right)^{\gamma}+\left(l_{t}^{m}\right)^{\gamma}}
\end{gathered}
$$

Under restriction (5), it is straightforward that $l_{t}^{f}<1$, hence (7a) holds with equality. (7b) holds with equality if the optimal choice on $l_{t}^{m}$ is interior $\left(l_{t}^{m}<1\right)$. The analysis is restricted to that case. It leads to a relationship between the optimal values of $l_{t}^{m}$ and $l_{t}^{f}$ :

$$
l_{t}^{m}=\left(\frac{h\left(e_{t}^{f}\right)}{h\left(e_{t}^{m}\right)+b}\right)^{\frac{1}{1-\gamma}} l_{t}^{f}
$$

This describes the share of housework between men and women. It consists in the equalization between the relative productivity of men at home: $\left(l_{t}^{m} / l_{t}^{f}\right)^{1-\gamma}$ and the relative opportunity cost of housework: $\left(h\left(e_{t}^{m}\right)+b\right) / h\left(e_{t}^{f}\right)$. Consequently, higher is the relative productivity of men on the labor market, higher is the relative time of women devoted to the production of the domestic good.

The total amount of human capital of a couple of the generation $t$ is: $h_{t}=h\left(e_{t}^{f}\right)+h\left(e_{t}^{m}\right)$. The FOCs (7b) and (7a) and the budget constraint (6) 
allow to obtain the expressions of $l_{t}^{f}$ and $l_{t}^{m}$ :

$$
\begin{gathered}
l_{t}^{f}=\frac{\gamma(1-\mu)}{\mu+\gamma(1-\mu)} \frac{h_{t}+b-\tau\left[e_{t+1}^{f}+e_{t+1}^{m}\right]}{h\left(e_{t}^{f}\right)\left[1+\left(\frac{h\left(e_{t}^{f}\right)}{h\left(e_{t}^{m}\right)+b}\right)^{\frac{\gamma}{1-\gamma}}\right]} \\
l_{t}^{m}=\frac{\gamma(1-\mu)}{\mu+\gamma(1-\mu)} \frac{h_{t}+b-\tau\left[e_{t+1}^{f}+e_{t+1}^{m}\right]}{\left(h\left(e_{t}^{m}\right)+b\right)\left[1+\left(\frac{h\left(e_{t}^{m}\right)+b}{h\left(e_{t}^{f}\right)}\right)^{\frac{\gamma}{1-\gamma}}\right]}
\end{gathered}
$$

It results in an expression of the optimal level of consumption:

$$
C_{t}=\frac{\mu}{\mu+\gamma(1-\mu)}\left(h_{t}+b-\tau\left[e_{t+1}^{f}+e_{t+1}^{m}\right]\right)
$$

The optimal share between housework and work on the market being given for the two spouses, the following section focuses on the optimal education choices.

\subsection{Educational choices}

Let consider the optimization with respect to the education of children, $e_{t+1}^{m}$ and $e_{t+1}^{f}$ :

$$
\begin{aligned}
\frac{h^{\prime}\left(e_{t+1}^{f}\right)}{h\left(e_{t+1}^{f}\right)} & \leq \frac{\tau \mu}{\beta \theta_{t} C_{t}} \\
\frac{h^{\prime}\left(e_{t+1}^{m}\right)}{h\left(e_{t+1}^{m}\right)} & \leq \frac{\tau \mu}{\beta C_{t}}
\end{aligned}
$$

(11a) (respectively $(11 \mathrm{~b})$ ) holds with equality if the optimal value of $e_{t+1}^{f}$ (respectively $e_{t+1}^{m}$ ) is strictly positive.

From now on, the following form for the function $h(e)$ is assumed:

$$
h\left(e_{t}^{i}\right)=c+a e_{t}^{i}
$$

As previously mentioned, this expression prevents human capital from being zero even if parents do not invest in education. The level of human capital is 
a linear function of the level of education ${ }^{11}, c>0$ embodies the productivity of workers' basic mental skills while $a>0$, is a measure of the education's productivity.

Using (10) and (12), (11a) and (11b) can be rewritten as:

$$
\begin{gathered}
h_{t}+b \leq \frac{\tau}{a \beta \theta_{t}}\left(c+a e_{t+1}^{f}\right)+\tau\left[e_{t+1}^{f}+e_{t+1}^{m}\right] \\
h_{t}+b \leq \frac{\tau}{a \beta}\left(c+a e_{t+1}^{m}\right)+\tau\left[e_{t+1}^{f}+e_{t+1}^{m}\right]
\end{gathered}
$$

The following sub-section focuses on the optimal choices of education in the case of an interior solution and in the case of a corner solution.

\subsubsection{Interior solution}

The optimal choices of education lead to an interior solution if both (13a) and $(13 \mathrm{~b})$ hold with equality. In this case, the ratio (13a) over (13b) yields:

$$
\frac{c+a e_{t+1}^{m}}{c+a e_{t+1}^{f}}=\frac{1}{\theta_{t}}
$$

This ratio measures the educational gap between men and women. It is a decreasing and convex function of $\theta_{t}$. Indeed, a high value of $\theta_{t}$ implies that the weight associated with girls education in parental preferences is close to the weight associated with boys education. It induces a relatively equal endowment for boys and for girls and a small educational gender gap.

The optimal level of education for a girl and a boy are deduced from (13a), (13b) and (14):

$$
\begin{aligned}
e_{t+1}^{f} & =\frac{a \beta \theta_{t}\left(h_{t}+b\right)-\tau c\left(1+\beta\left(1-\theta_{t}\right)\right)}{a \tau\left(1+\beta\left(1+\theta_{t}\right)\right)} \\
e_{t+1}^{m} & =\frac{a \beta\left(h_{t}+b\right)-\tau c\left(1-\beta\left(1-\theta_{t}\right)\right)}{a \tau\left(1+\beta\left(1+\theta_{t}\right)\right)}
\end{aligned}
$$

\footnotetext{
${ }^{11}$ Results are unaffected if decreasing returns of education are assumed. However, the assumption of constant returns in education simplify the exposition.
} 


\subsubsection{Corner solutions}

From (13a) and (13b), parents choose to educate only their son if:

$$
h_{t}<\frac{(1+\beta) \tau c-\beta \theta_{t}(\tau c+a b)}{a \beta \theta_{t}} \equiv \tilde{h}\left(\theta_{t}\right)
$$

In that case the optimal value of $e_{t+1}^{m}$ is the following:

$$
e_{t+1}^{m}=\frac{a \beta\left(h_{t}+b\right)-\tau c}{a \tau(1+\beta)}
$$

$\tilde{h}\left(\theta_{t}\right)$ is decreasing and convex in $\theta_{t}$, with $\tilde{h}(1)=\tau c / a \beta-b$ and $\lim _{\theta_{t} \rightarrow 0} \tilde{h}\left(\theta_{t}\right)=$ $+\infty$.

Since $\theta_{t} \leq 1$, the symmetric case $\left(e_{t+1}^{f}>0\right.$ and $\left.e_{t+1}^{m}=0\right)$ never occurs. Finally, if both (13a) and (13b) hold with inequality when $e_{t+1}^{f}=0$ and $e_{t+1}^{m}=0$, parents give no education to their children. It is the case if:

$$
h_{t}<\frac{\tau c}{a \beta}-b=\tilde{h}(1)
$$

Then, the plan $\left(\theta_{t}, h_{t}\right)$ can be divided as depicted in Figure 1.

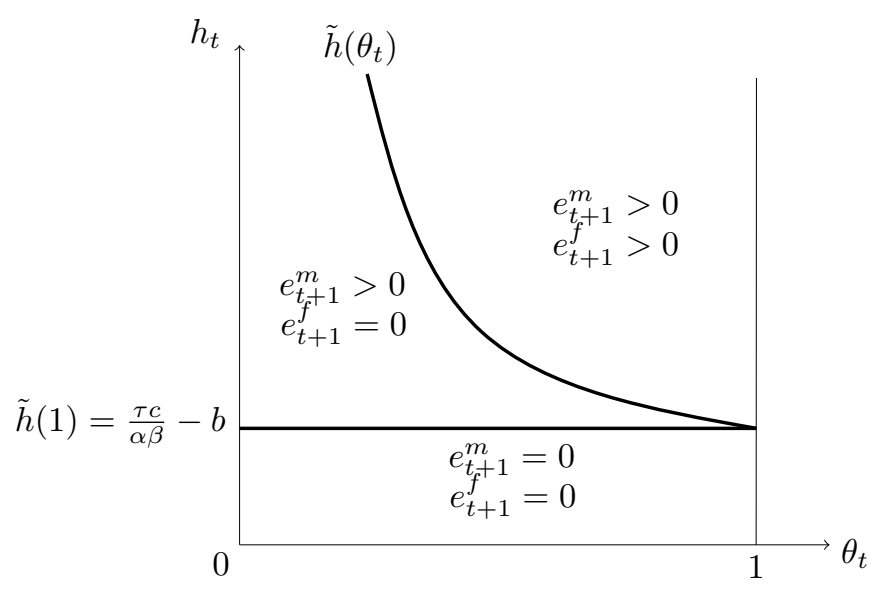

Fig. 1. Corner solutions in education

If $h_{t}$ is too low (lower than $\tilde{h}(1)$ ), parents choose to provide no education to their children. The economy is in the poverty regime. For intermediary 
values of income $\left(h_{t} \in\left[\tilde{h}(1), \tilde{h}\left(\theta_{t}\right)\right]\right)$, only boys are educated. It corresponds to the gender inequality regime. Finally, for a large enough level of development $\left(h_{t}>\tilde{h}\left(\theta_{t}\right)\right)$ both boys and girls receive education. It is the interior regime.

Notice that, for a given value of $h_{t}$, the probability to be in the gender inequality regime decreases with $\theta_{t}\left(\tilde{h}\left(\theta_{t}\right)\right.$ is decreasing in $\left.\theta_{t}\right)$. Indeed, if $\theta_{t}$ is low, the importance of girls education in parental preferences is small. Consequently, the level of development required for the education of women is high.

\subsection{Evolution of human capital}

From the previous section, it follows that optimal levels of education $e_{t+1}^{f}$ and $e_{t+1}^{m}$ depend on $h_{t}, \theta_{t}$ and parameters of the model. It implies that the total level of human capital at date $t+1\left(h_{t+1}\right)$ is a function of $h_{t}$ and $\theta_{t}$. Let define the function $\chi\left(\theta_{t}\right)$ as follows:

$$
\chi\left(\theta_{t}\right) \equiv \frac{\beta}{\tau\left(1+\beta\left(1+\theta_{t}\right)\right)}
$$

It directly comes from (12) and (15a)-(19) that:

$$
\begin{array}{r}
h\left(e_{t+1}^{f}\right)=\left\{\begin{array}{lll}
c & \text { if } h_{t}<\tilde{h}(1) \\
c & \text { if } h_{t} \in\left[\tilde{h}(1), \tilde{h}\left(\theta_{t}\right)\right] \\
\chi\left(\theta_{t}\right) \theta_{t}\left[a\left(h_{t}+b\right)+2 \tau c\right] & \text { if } h_{t}>\tilde{h}\left(\theta_{t}\right)
\end{array}\right. \\
h\left(e_{t+1}^{m}\right)=\left\{\begin{array}{lll}
c & \text { if } h_{t}<\tilde{h}(1) \\
\chi(0)\left[a\left(h_{t}+b\right)+\tau c\right] & \text { if } h_{t} \in\left[\tilde{h}(1), \tilde{h}\left(\theta_{t}\right)\right] \\
\chi\left(\theta_{t}\right)\left[a\left(h_{t}+b\right)+2 \tau c\right] & \text { if } h_{t}>\tilde{h}\left(\theta_{t}\right)
\end{array}\right.
\end{array}
$$

As a consequence:

$$
h_{t+1}=\left\{\begin{array}{lll}
2 c & \text { if } \quad h_{t}<\tilde{h}(1) \\
c+\chi(0)\left[a\left(h_{t}+b\right)+\tau c\right] & \text { if } \quad h_{t} \in\left[\tilde{h}(1), \tilde{h}\left(\theta_{t}\right)\right] \equiv \rho\left(h_{t}, \theta_{t}\right) \\
\chi\left(\theta_{t}\right)\left(1+\theta_{t}\right)\left[a\left(h_{t}+b\right)+2 \tau c\right] & \text { if } \quad h_{t}>\tilde{h}\left(\theta_{t}\right)
\end{array}\right.
$$

The dynamics of $h_{t}$ is characterized by the three regimes described previously. In the poverty regime, there are no education, then $h_{t}$ remains constant. In the gender inequality regime, the rise in $h_{t}$ is driven by the increase of men's 
education. In the interior regime, the education of both men and women enable the increase of human capital.

In interior and gender inequality regimes, $h_{t+1}$ is a linear function of $h_{t}$. Then, the dynamics of $h_{t}$ exhibits a steady state only if the slope of $h_{t+1}$ with respect to $h_{t}$ is lower than unity. A sufficient condition for the existence of a steady state in both interior and gender inequality regimes is:

$$
\tau>\frac{2 \beta}{1+2 \beta} a
$$

It implies that the costs of education are not too low with respect to the returns of education. ${ }^{12}$

\subsection{Evolution of the gender roles}

The parameter $\theta_{t}$ is a measure of the parental bias towards boys. This cultural parameter is composed of a fast-moving component and a slowmoving one:

$$
\theta_{t}=(1-\lambda) \psi_{t}
$$

$\lambda \in(0,1)$, captures the exogenous (slow-moving) part of the norm. If $\lambda$ is great, the views about gender roles remain inegalitarian whatever the participation of women on the labor market. $\psi_{t}$ represents the endogenous (fastmoving) part of the norm. It depends both on $\psi_{t-1}$, the existing norm within the previous generation (due to the intergenerational transmission of gender role attitudes), and the ratio $l_{t}^{f} / l_{t}^{m}$ (i.e. the relative time spent by women to work at home). Indeed, the observation by parents of a change in women participation induces an evolution of their view of gender role. If $l_{t}^{f} / l_{t}^{m}$ increases, the role of women is more associated to housework, then the education of the daughter is less valued. Formally, it is assumed that:

$$
\psi_{t}=\sigma \psi_{t-1}+(1-\sigma)\left(l_{t}^{m} / l_{t}^{f}\right)^{\kappa}
$$

The parameter $\sigma \in(0,1)$ measures the strength of habits. Higher is $\sigma$, the more persistent is the gender bias. Expressions (23) and (24) joint with condition (14) imply that an increase in the relative labor supply of men induces a decrease of the relative investment in girls education. This result

\footnotetext{
${ }^{12}$ This condition is no more needed in the case of decreasing returns of education.
} 
can be supported, for instance, by the findings of Rosenzweig and Schultz (1982) on Indian's data. From (8), it results that:

$$
\theta_{t+1}=\sigma \theta_{t}+(1-\sigma)(1-\lambda)\left(\frac{h\left(e_{t+1}^{f}\right)}{h\left(e_{t+1}^{m}\right)+b}\right)^{\frac{\kappa}{1-\gamma}}
$$

It follows from (20a) and (20b) that $\theta_{t+1}$ can be expressed as a function of $\theta_{t}$ and $h_{t}$ so that $\theta_{t+1}=\eta\left(h_{t}, \theta_{t}\right)$.

\section{The dynamical system}

The development of the economy is characterized by the trajectories of the human capital $\left(h_{t}\right)$ and gender roles attitudes $\left(\theta_{t}\right)$. Then, the sequence $\left\{h_{t}, \theta_{t}\right\}_{t=0}^{\infty}$ determines the dynamic path of the economy. It is driven by a bi-dimensional, first-order dynamical system given by equation (21) and (25):

$$
\left\{\begin{array}{l}
h_{t+1}=\rho\left(h_{t}, \theta_{t}\right) \\
\theta_{t+1}=\eta\left(h_{t}, \theta_{t}\right)
\end{array}\right.
$$

where $h_{0}$ and $\theta_{0}$ are given. The analysis of the system requires the derivation of its phase diagram. The first step is to characterize the $h h$ and $\theta \theta$ loci where $h_{t}$ and $\theta_{t}$ are respectively in a steady state.

\subsection{The $h$ h locus}

Let $h h$ be the locus of all pairs $\left(h_{t}, \theta_{t}\right)$ such that $h_{t}$ is constant: $h h \equiv\left\{\left(h_{t}, \theta_{t}\right)\right.$ : $\left.h_{t+1}=h_{t}\right\}$. Features of this locus depend on the regime which characterized the economy. Later on, the three regimes are successively considered. Figure 2 is deduced from the analysis of the $h h$ locus (see Appendix A).

The horizontal line $h_{t}=2 c$ corresponds to the $h h$ locus in the poverty regime. Indeed, in this regime there are no education and the total amount of human capital is constant and equal to 2 . In the case (b), $\tilde{h}(1)<2 c$ then the horizontal line $h_{t}=2 c$ is no more in the poverty regime. Thus, even if there is initially no education in the economy, the accumulation of human capital is possible and the economy always escape from the poverty regime. 


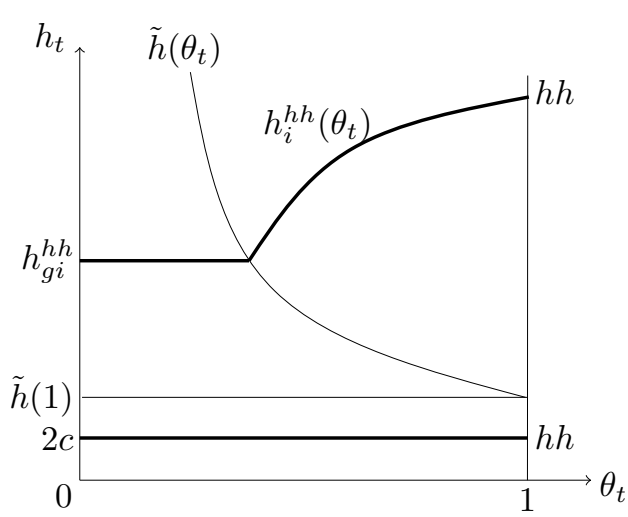

(a) $\tilde{h}(1)>2 c$

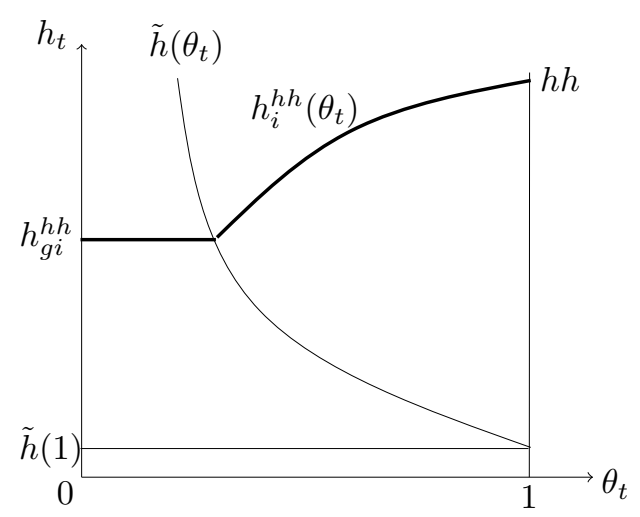

(b) $\tilde{h}(1)<2 c$

Fig. 2. The hh locus

In the gender inequality regime, the accumulation of human capital is only driven by the education of men. Then, $h_{t+1}$ is a function of $h_{t}$ but is unaffected by the value of $\theta_{t}$ (see expression (21)). When condition (22) is satisfied, $h_{t}$ converges towards a constant value $h_{g i}^{h h}$, independent of $\theta_{t}{ }^{13}$

In the interior regime, both men and women are educated. Since a rise of $\theta_{t}$ induces an increase in the overall weight of education in the utility of parents, it implies an augmentation of the total investment in education. It follows that the stationary value of human capital (denoted $h_{i}^{h h}\left(\theta_{t}\right)$ ) is an increasing function of $\theta_{t}$.

\subsection{The $\theta \theta$ locus}

Let $\theta \theta$ be the locus of all pairs $\left(h_{t}, \theta_{t}\right)$ such that $\theta_{t}$ is constant: $\theta \theta \equiv\left\{\left(h_{t}, \theta_{t}\right)\right.$ : $\left.\theta_{t+1}=\theta_{t}\right\}$. Condition (27) is assumed to hold in the following, such that Figure 3 depicts the $\theta \theta$ locus (see Appendix B).

$$
\kappa<1-\gamma
$$

The level of $h_{t}$ influences the locus of stationarity of $\theta$ through its effect on the relative labor supply of men and women. In the poverty regime, this

\footnotetext{
${ }^{13} h_{r}^{l}$ denotes the value of human capital on the locus $l \in\{h h, \theta \theta\}$ in the regime $r \in\{g i, i\}$ (gi denotes the gender inequality regime and $i$ the interior regime).
} 


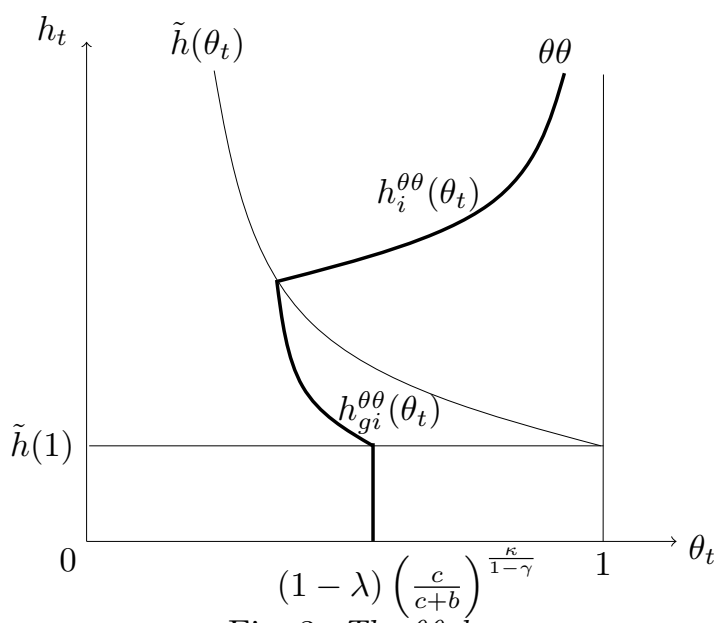

Fig. 3. The $\theta \theta$ locus

relative labor supply is exogenous, independent of $h_{t}$, then the locus consists in a vertical line.

In the gender inequality regime, an increase of $h_{t}$ induces a rise of the level of education of men, while this level remains constant for women. Then, the relative productivity of men on the labor market, and consequently their relative labor supply, is increasing in $h_{t}$. Hence, the level of $\theta_{t}$ which ensures its stationarity decreases with $h_{t}$.

In the interior regime, an increase of $h_{t}$ induces a rise of the education for both men and women. It increases the relative productivity of women and then their relative labor supply. In this case, the level of $\theta_{t}$ which corresponds to stationarity increases with $h_{t}$.

\subsection{Steady state equilibria}

Steady-state equilibria of the dynamical system are pairs $\{\bar{h}, \bar{\theta}\}$ such that:

$$
\left\{\begin{array}{l}
\bar{h}=\rho(\bar{h}, \bar{\theta}) \\
\bar{\theta}=\eta(\bar{h}, \bar{\theta})
\end{array}\right.
$$

It consists in the intersections between the $h h$ and the $\theta \theta$ locus. Through representations of the two loci (Figure 2 and 3), it follows:

Proposition 1 Under conditions (22) and (27), The steady states of the dynamic system (26) display the following features: 
$i$ (a) if $\tilde{h}(1)>2 c$, there exists a locally stable equilibrium in the poverty regime; (b) if $\tilde{h}(1)<2 c$, there are no steady sate in the poverty regime;

ii in addition, there are at least: (1) one equilibrium in the gender inequality regime, if it is unique, it is globally stable; or (2) one equilibrium in the interior regime, if it is unique, it is globally stable; and, at most (3) three equilibria, one locally stable in the gender inequality regime, one locally stable in the interior regime, and the last unstable.

\section{Proof See Appendix D}

If $\tilde{h}(1)>2 c$, it directly follows from Figures $2(\mathrm{a})$ and 3 that the $h h$ locus and the $\theta \theta$ locus cross once in the poverty regime. It results in the existence of one equilibrium in this regime, namely the poverty trap. This equilibrium is locally stable so that, if the initial level of human capital is lower than $\tilde{h}(1)$ the economy converges towards a situation without education $\left(h_{\infty}=2 c\right)$ and in which $\theta_{\infty}=(1-\lambda)[c /(c+b)]^{\kappa /(1-\gamma)}<1$.

Consider the case in which $\tilde{h}(1)<2 c$. From Proposition 1 , the dynamic system (26) exhibits either one globally stable equilibrium in the gender inequality regime (Figure 4(a)), or one globally stable equilibrium in the interior regime (Figure 4(b)). The stable equilibrium in the gender inequality regime is named the inegalitarian steady state. It is characterized by a high level of gender inequality, since only men are educated, and a level of human capital equal to $h_{g i}^{h h}$. The stable equilibrium in the interior regime is named the high-output steady state. It is characterized by a relative equality between men and women (both are educated) and high level of human capital.

Notice that, an intermediary configuration could arise in which both the high-output and the inegalitarian steady states are locally stable (see Figure $5)$.

\subsection{Comparative statics}

As previously mentionned, a poverty trap exists only if $\tilde{h}(1)>2 c$, that is under the condition:

$$
\tau>(2 c+b) a \beta / c
$$

It follows that, either a decrease in $\tau$ or an increase in the productivity parameters $(a$ or $b)$ allow to escape from the poverty trap. Conversely, the 

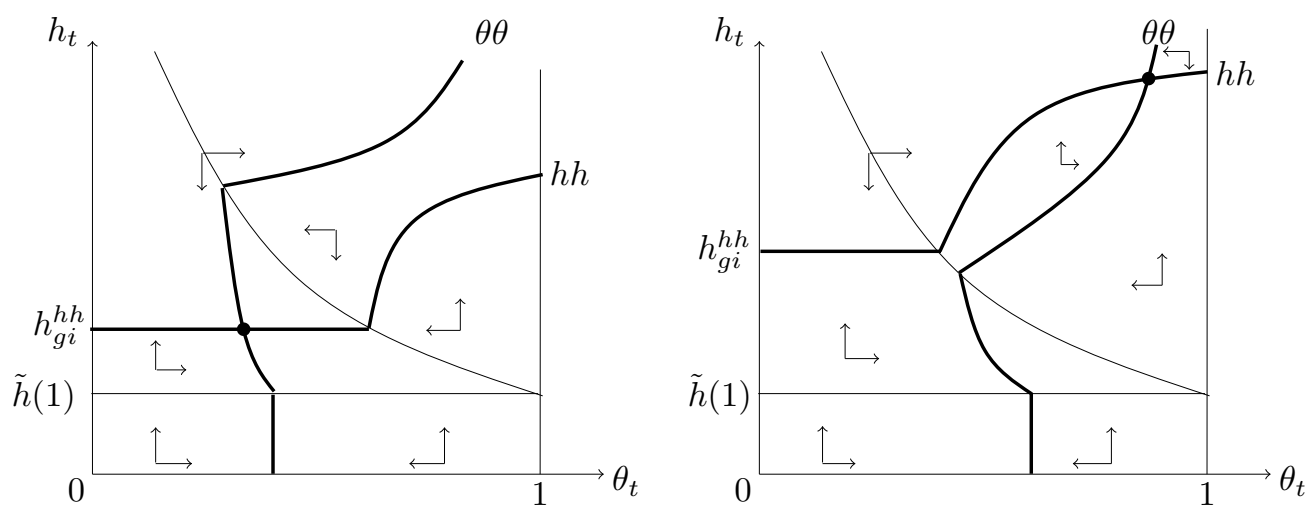

(a) The inegalitarian equilibrium is globally stable (b) The high-output equilibrium is globally stable Fig. 4. Phase diagrams when only one equilibrium is globally stable

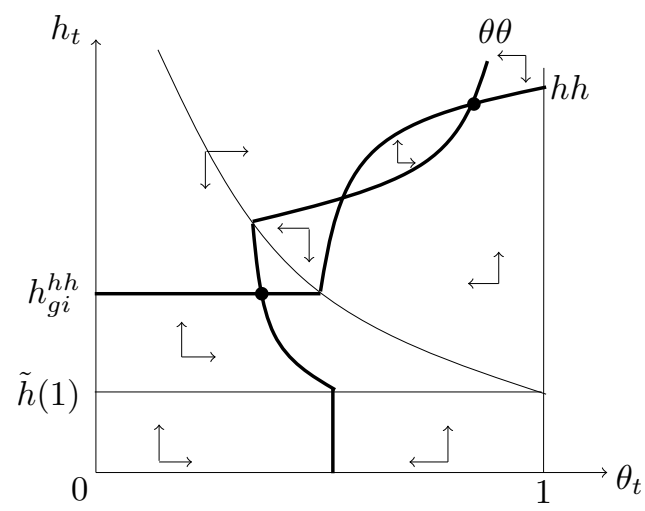

Fig. 5. The inegalitarian and high-output steady states are both locally stables

cultural parameter $\lambda$ does not impact on the probability of occurence of the trap. The effect of a rise in $c$ on the possibility to escape from the poverty trap is ambigous. On one hand, it allows to reach a higher level of development (upward shift of the $h h$ locus) and then to step out from the poverty regime. On the other hand, increasing the productivity of basic skills, it reduces the incentives to invest in education (upward shift of $\tilde{h}\left(\theta_{t}\right)$ ).

The two following lemmas expose the consequences of changes in main parameters on the inegalitarian and high-output equilibria respectively.

Lemma 1 Under conditions (22) and (27): 
$i$ An increase in a (as a decrease in $\tau$ ) makes the inegalitarian equilibrium more unequal but characterized by a higher level of human capital.

ii An increase in c has an ambigous effect on the level of inequality at the inegalitarian equilibrium, however it rises the level of human capital.

iii An increase in $\lambda$ makes the inegalitarian equilibrium more unequal and leave the level of human capital unchanged.

An increase in $a$ corresponds to a rise of the productivity of education. It is straighforward that it implies an upward shift of the $h h$ locus. It also induces a shift towards the left of the $\theta \theta$ locus in the gender inequality regime. Indeed, in this regime, only men are educated and then take advantage of the increase of $a$. It implies an augmentation of the relative advantage of men on the labor market which, in turn, decreases the relative labor supply of women. Consequently, the level of $\theta_{t}$ which corresponds to stationarity decreases in $a$. The same mechanisms apply in the case of a fall of $\tau$.

A rise of the productivity of basic skills (c) has two opposite effects on inequalities at the inegalitarian equilibrium. On one hand, it implies an upward shift of the $h h$ locus which induces an augmentation of the level of human capital and the level of inequality. Indeed, the increase of $h_{t}$ enables a higher education for the boys and, since girls receive no education, an increase in the gender gap. On the other hand, men and women share the same level of basic skills. Then an increase of $c$ implies a reduction of the weight of physical strenght and education in labor productivity which in turn increases the relative labor supply of women.

The level of $\lambda$ does not affect the $h h$ locus. However, a rise of $\lambda$ makes the slow moving compoment of the cultutral norm more inegalitarian. It follows a shift towards the left of the $\theta \theta$ locus.

Lemma 2 Under conditions (22) and (27):

$i$ An increase in a (as a decrease of $\tau$ ) makes the high-output equilibrium less unequal and characterized by a higher level of human capital.

ii An increase in c makes the high-output equilibrium less unequal and characterized by a higher level of human capital. 
iii An increase in $\lambda$ makes the inegalitarian equilibrium more unequal and characterized by a lower level of human capital.

In the interior regime both men and women receive education, a rise of $a$ (as a rise of $c$ or a decrease of $\tau$ ) induces a decreases in the relative wheight of physical strenght in labor productivity. It generates an increase of the relative labor supply of women and a shift towards the right of the $\theta \theta$ locus. A positive shock on productivity parameters $(a$ and $c$ ) or a negative shock on costs of education $(\tau)$ also increases the level of human capital at the stationary equilibrium. Since the level of $\theta_{t}$ which corresponds to stationarity in the interior regime is increasing in $h_{t}$, the rise in the level of human capital reincorces the fall of the gender gap due to the displacement of the $\theta \theta$ locus.

The effect of an increase of $\lambda$ on two loci is the same than in the gender inequality regime: hh locus unchanged and $\theta \theta$ locus translated towards the left. However, in the interior regime, the decrease of the stationary value of $\theta_{t}$ implies a lower level of human capital at the steady state. Indeed, $\theta_{t}$ corresponds to the value given to the education of girls, if $\theta_{t}$ is low, girls receive few education and the $h_{t}$ is low too.

It follows from Lemmas 1 and 2 some conditions under which the economy exhibits a unique high-output equilibrium. These conditions are exposed in Proposition 2.

Proposition 2 Under conditions (22) and (27):

$i$ Economies with sufficiently high value of a or sufficiently low value of $\tau$ will exhibit a unique high-output equilibrium.

ii A low level of $\lambda$ increases the probability that an economy exhibit a unique high-output equilibrium.

If the increase of $a$ is high enough, the upward shift of the $h h$ locus is sufficiently large and the inegalitarian equilibrium disapears. In that case the accumulation of human capital allows to escape from the gender inequality regime and the economy converges towards the unique high-output equilibrium. Same results apply for a sufficiently large reduction of $\tau$. As pointed out in Lemma 1, a negative shock on $\lambda$ induces a shift towards the right of the $\theta \theta$ locus. It may imply a disapearance of the inegalitarian equilibrium. 
Indeed, for a given level of human capital, less traditional are the views about gender roles, higher are the incentives to educate girls. However, a change in $\lambda$ is not always sufficient to induce the convergence towards the high-output equilibrium. Indeed, due to difference in physical strenght's endowments between men and women, the cultural norm is inegalitarian even if $\lambda=0$.

Notice that, as in the case of the poverty trap, the effect of $c$ on the possibilities of step out from the gender inequality equilibrium is ambigous. Indeed, it increases the level of development and then the possibility to invest in human capital however it reduces the incentives to invest in education. Consequently, the level of human capital required to educate girls increases with $c$.

\section{The dynamic pattern of development}

This section deals with the dynamic consequences of technical progress for an economy initially poor. Without loss of generality, it focuses on the case in which $\lambda=0$, i.e. views about gender roles are fully endogenous.

\subsection{Escape from the poverty trap}

Consider an economy characterized by a low technological level (such that $\tilde{h}(1)>2 c$ ) and is initially poor (such that $h_{0}<\tilde{h}(1)$ ). As depicted in Figure 7 , this economy remains trapped in a low-output equilibrium.

In this situation, there is no education expenditures in the economy. Individuals are only endowed with their basic mental skills and, for men, with physical strength. Thanks to this physical strength, men are more productive than women on the labor market, then their level of participation is higher. These differences in the labor supply shape individuals beliefs about gender roles. Since the relative labor supply is constant, the parameter $\theta$ progressively converges towards a stationary value $(\bar{\theta})$. Higher is $b$ (the endowment in physical strength), higher is the relative labor supply of men, thus the more inegalitarian are views about gender roles. Consequently, if a technical improvement allows to step out from the poverty trap, parents will favor the education of boys with respect to the education of girls.

Notice that, in the configuration depicted in Figure 7, another locally stable equilibrium could exist: the inegalitarian steady-state. However, the 


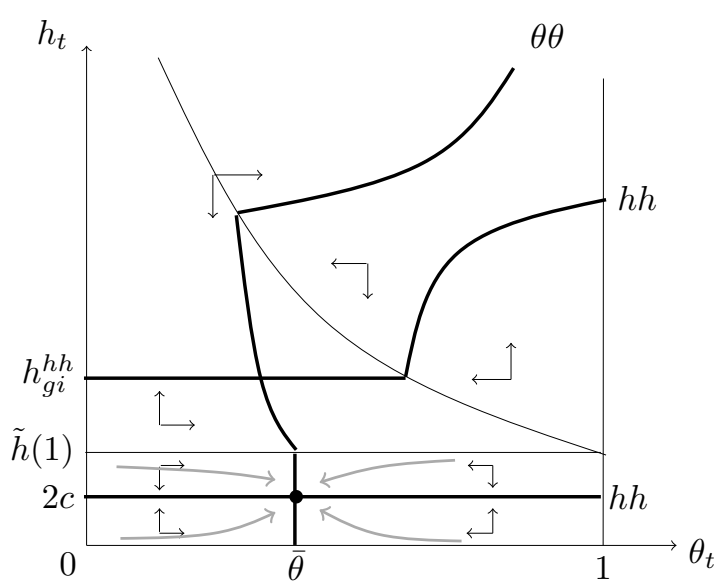

Fig. 6. Dynamics when a is low: Convergence towards the poverty trap

economy cannot escape from the poverty trap without an exogenous shock lowering $\tilde{h}(1)$. From (29) such a shock could be an increase of technological level $(a$ or $b)$ or a fall of education costs $(\tau)$. Consider the case of an increase of $a$, if it is large enough to ensure that $\tilde{h}(1)$ becomes lower than $2 c$, the economy escapes from the poverty trap. In that case, the dynamics of the economy is characterized by one of the three situations depicted in section 5.3. The long-run behavior of the economy depends on the range of the technological improvement (increase of $a$ ).

From Proposition 2, for a large enough increase of $a$, the dynamics is depicted by Figure 4(b) and the economy converges towards the high-output steady state. Starting from the situation of Figure 7, this last case is illustrated in Figure 8. It represents the consequences of a shock such that the new technological level $\left(a^{\prime}\right)$ is sufficiently high to ensure the global stability of the high-output steady state.

In this situation, the accumulation of human capital enables to escape from the gender inequality regime and parents begin to educate their daughter. It follows an increase of the relative productivity of women. Consequently, the relative labor supply of men decreases and beliefs about gender roles become less traditional ( $\theta_{t}$ increases). In the long-run, the economy converges towards the high-output equilibrium characterized by a relatively large equality between gender. Notice that, the equality is never complete since it remains the initial differences of productivity due to the physical 


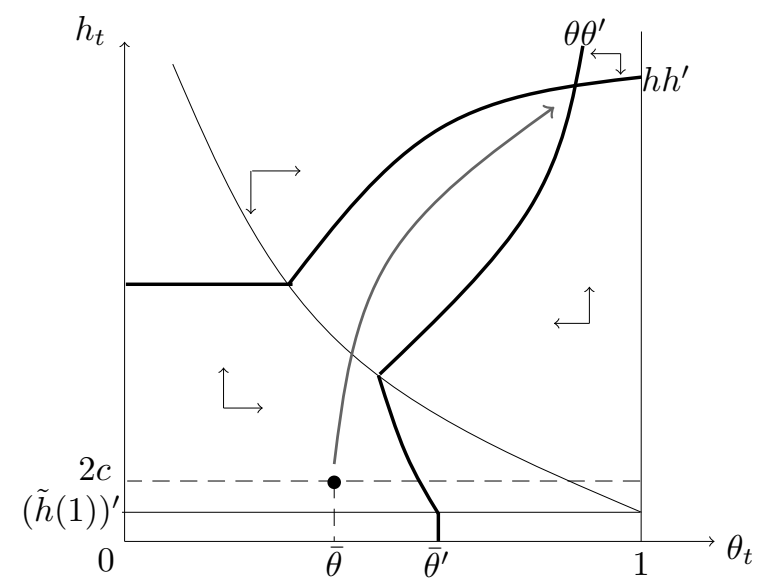

Fig. 7. Dynamics when a is high: Convergence towards the high-output equilibrium

strength. However, the accumulation of education reduces the weight of this initial difference.

\subsection{U-shaped female labor participation}

Several studies point out a U-shaped relationship between women labor supply and economic development both in cross country and on longitudinal data. Mammen and Paxson (2000) explain this pattern as follows: "For very poor countries, female labor force participation is high, and women work mainly in farm and non-farm family enterprises. Development initially moves women out of the labor force, partly because of the rise in men's market opportunities and partly because of social barriers against women entering the paid labor force. However, as countries continue to develop, women's education level rise, and women move back into the labor force". The present model aims at replicating this pattern. As Mammen and Paxson (2000) and Goldin (1995), it insists on the role of social norms as an explanation of these evolutions. Indeed, the inegalitarian social norms imply that, in the first stage of development, only men are educated. It follows that the relative opportunities of men on the labor market rise and the women labor supply falls. The rise of women education inverses this trend since it induces the reduction of the productivity gap between men and women.

The model leads to the same conclusions from a cross-country point of 
view. Indeed, the dynamics exhibits potentially three steady states, each one corresponding to a stage of development. The poverty trap, characterized by a low level of human capital, is located in the left part of the U. At the inegalitarian equilibrium, the level of development is higher and the women labor supply is lower (at the bottom of the U curve). Finally, the high-output equilibrium corresponds to the right part of the $\mathrm{U}$.

Notice that, the initial increase of women's housework rises the relative productivity of men's housework. This effect could induce a decrease of men's labor participation in the first stage of development (see expression (8)). However, it should be compensate by the sharp increase in the relative productivity of men on the market. In the second stage of development (rising part of the U), a slight decrease of the men's labor supply may occur due to the decrease of their relative productivity on the market.

\section{Slow-moving social norms}

This section focuses on the role played by the slow moving compoment of cultural norms (captured by the parameter $\lambda$ ) on the long-run situation reached by the economy. As mentioned in section 5.4, an increase in $\lambda$ has no consequences on the $h h$ locus but shifts the $\theta \theta$ locus towards the left. Then, two countries having the same technological characteristics but which differ by their level of $\lambda$ could converge towards different situations. Such a case is illustrated in Figure 8.

In the country (b), the conservative slow moving component of culture is reinforced by the fast moving component during the process of development. As a consequence, the country cannot escape from the gender inequality regime.

One possible interpretation of the parameter $\lambda$ is the weight attached to the religion. Guiso et al. (2006) point out that religion could be considered as an exogenous social norm or, at least, as a slow moving component of culture. $^{14}$ Moreover, Guiso et al. (2003) show that religiosity is positively

\footnotetext{
${ }^{14}$ Assuming that religion is an exogenous variable is obviously a first approximation. Indeed, economic development also affect religious particpation (see McCleary and Barro
} 


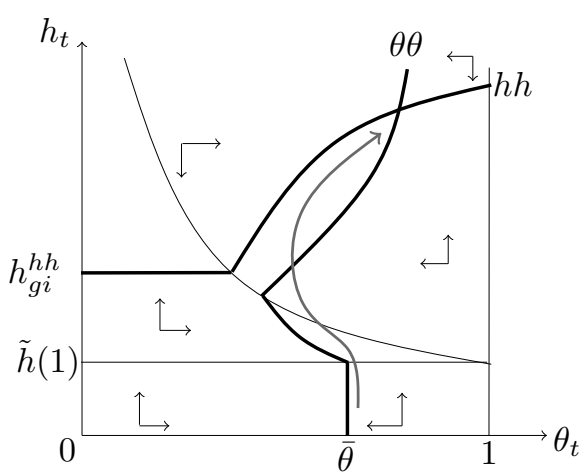

(a) $\lambda=0$

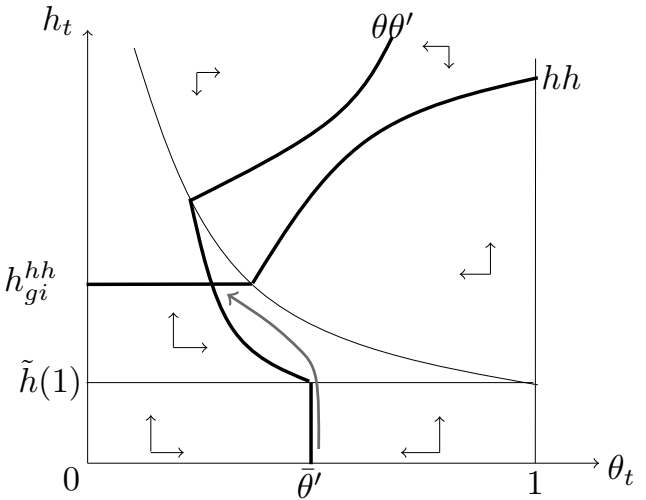

(b) $\lambda=\lambda^{\prime}>0$

Fig. 8. The impact of $\lambda$

related with conservative attitudes towards women. Following this interpretation, the model predicts that a society in which the weight of religious values is important will be characterized by larger gender inequality. This result complies with findings of Inglehart and Norris (2003) which point out that societies based on religious values are most likely to exhibit a strong gender gap and a low acceptance of gender equality. In the same way Alesina and Giuliano (2007) find a negative relationship between religion and women labor force participation and that religion reinforces the traditional views about gender roles. Finally, Dollar and Gatti (1999) conclude that gender differences in educational achievement partly result from religious preferences.

Taking the example of the second Vatican council, Guiso et al. (2003) show that a change in religious doctrine can reduce the conservative attitudes against women. The model predicts that such a cultural change could have a long-run impact both on the level of gender inequality and the level of economic development.

(2006) for a discussion on the two-way interaction between religion and economic outcomes). The model could be extended in considering the parameter $\lambda$ as endogenous but in taking into account that the adjustement of $\lambda$ is slower than the variations of $\psi$. 


\section{Foreign Direct Investments and evolution of the gender gap}

As previously discussed, changes in productivity parameters have strong implications on the evolution of the gender gap. In the context of developing countries, Foreign Direct Investments (hereafter FDI) constitute a key variable in the change of technological and productivity levels. While the relationship between FDI and economic growth has been deeply investigated, their impact on gender inequalities is poorly known. A noticeable exception is the recent study of Oostendorp (2004) which points out the different consequences of FDI with respect to the developement level of the host country and the skills level of the concerned sectors. In particular, the author concludes to a narrowing impact of FDI net inflows on the gender gap for low-skill occupations both in poor and rich countries and for high-skill occupations in rich countries; while he finds a widening impact on the high-skill occupational gender gap in poor countries. ${ }^{15}$

The present model provides explanations to this puzzle. In our framework, the impact of a FDI net inflows' rise on low-skill (respectively highskill) occupations is approximated by the augmentation of the parameter $c$ (respectively $a$ ). Indeed, an increase of $c$ corresponds to a positive shock on basic skills while an increase of $a$ corresponds to a positive shock on returns to education. Lemmas 1 and 2 highlight the different impacts of these two shocks on the gender gap for a poor country (at the inegalitarian equilibrium) and a rich country (at the high-output equilibrium). While an increase in $c$ may reduce the gender gap for both equilibria, an increase in $a$ widens the gap at the gender inequality equilibrium and narrows it at the high-output equilibrium.

Notice that a decrease of the educational costs $(\tau)$ has the same consequences than an increase of $a$. In countries at the inegalitarian steady state, the reduction of $\tau$ allows for a better access to schooling for the boys and increase the gender gap (Lemma 1). However, if the fall is large enough, the economy escapes from the inegalitarian equilibrium and converges to the high-output one (Proposition 2). In that case, the gender gap narrows. At the high output equilibrium, a decrease of $\tau$ reduces the gender gap (Lemma

\footnotetext{
${ }^{15}$ The author uses data from the ILO october inquiry for the period 1983-1999. High-skill occupations are defined as those occupations in the bottom half of the wage distribution.
} 
$2)$.

\section{Discussion}

This section discusses possible extensions of the basic model. Specifically, the following possibilities are successively addressed: (i) women are discriminated on the labor market, (ii) the technological progress evolves endogenously, and (iii) the choices of fertility are endogenous.

\subsection{Discrimination on the labor market}

A consensus about the existence of discrimination against women on the labor market has progressively emerged in the economic literature (see Altonji and Blank (1999) for a survey). Taking into account this discrimination in the model does not qualitatively affect the results and allows to relax the assumption that men and women exhibit a difference in physical strength. Assume that, due to the discrimination, $w^{f}=h\left(e^{f}\right)-d$ while $w^{m}=h\left(e^{m}\right)$. The fact that the amount $d$ (which measures the level of discrimination) is unaffected by the level of human capital is a restrictive assumption. However, it complies with the Goldin (1995) thesis that the social stigma against working women decreases as the level of human capital increases. Notice that, $d$ can be alternatively regarded as a psychological cost suffered by women at work due to the social pressure.

The existence of a discrimination between men and women induces an exogenous gender gap. It plays the same role that the physical strength in the analysis. Consequently, results of the model are unaffected: Due to this initial gender gap, men work more on the market than women. It follows in an inegalitarian view of gender role which generates an extension of the gender gap in early stages of development.

The fact that the discrimination on the labor market can be internalized and lead to a change in the definition of gender roles is present in the articles of Escriche et al. (2004) and Escriche (2007). It modifies the economic policy implications of the model. Anti-discriminatory policies (inducing a reduction of $d$ ) allows to escape from the gender inequality trap and makes the highoutput equilibrium more egalitarian. However, such policies could not be sufficient to step out from the poverty trap. 


\subsection{Endogenous technical progress and the road to equal- ity}

As noticed in section 6.1 , the high-output equilibrium is characterized by a relative equality between men and women. However, at this equilibrium, the educational gender gap is not completely filled. This result is inconsistent with the actual situation of developed countries where the educational gender gap tends towards zero. The model can replicate the convergence of human capital levels of men and women considering the existence of technological progress. If $a$ grows at rate $g_{a}>0$, the weight of $b$ in the relative productivity of men and women progressively disappears and the level of girls' education converges towards the level of boys' education. However, as shown in section 6.1, a constant increase of $a$ implies the disappearance of the gender inequality trap.

One way to reconciliate the road to equality of developed countries with the possibility of inequality traps in developing countries is to consider that the technological progress is endogenous but that a sufficient level of human capital is required to engage the process. In line with Strulik (2003), the following formulation of technological progress is considered:

$$
\Delta a_{t}=\left\{\begin{array}{lll}
0 & \text { if } \quad h_{t}<\hat{h} \\
g_{a}\left(h_{t}\right) & \text { if } \quad h_{t} \geq \hat{h}
\end{array}\right.
$$

with $g_{a}\left(h_{t}\right) \geq 0 .{ }^{16}$ It implies that the endogenous technical progress gets under way only if the level of human capital is sufficiently high. Under this assumption and if $\hat{h}$ is higher than $h_{g i}^{h h}$ and lower than the human capital accumulated at the high equilibrium, the inegalitarian equilibrium is not destabilized and one economy which reaches the high equilibrium grows and takes the road to equality.

\subsection{Fertility behaviors}

A major weakness of the model is to consider fertility behaviors as exogenous. It avoids the possibility to study the fertility transition and to precisely calibrate the model. However, this restriction allows for focusing on the

\footnotetext{
${ }^{16}$ In order to satisfy the condition (22), the increase in a must be bounded. Under the assumption that $h\left(e_{t}^{i}\right)$ exhibits decreasing retruns, no restriction have to be impose on the function $g_{a}\left(h_{t}\right)$.
} 
share of domestic labor between men and women. Up to now, the two-sex dynamics models with endogenous fertility (Galor and Weil (1996), Lagerlöf (2003) or de la Croix and Vander Donckt (2008)) do not consider this aspect since they find a complete specialization of tasks within the household: Child rearing is devoted to women. In this framework, the women labor supply is directly linked with fertility behaviors since it consists in the time not spent to rear children.

A realistic middle way would be an endogenous fertility model in which both men and women can participate to child rearing. As the domestic production in the model, the production function of children could depend, in a non linear way, on $l^{f}$ and $l^{m}$. Such a model should be able to generate a period where both fertility decreases (due to the increase of the quantity cost) and women labor supply reduces (due to the rise of the gender productivity gap), during first stages of the transition from the Malthusian poverty trap to the high-output/low-fertility equilibrium.

\section{Conclusion}

Eliminate gender disparity in primary and secondary education is the forth Millennium Summit Development target. The reduction of the educational gender gap is an aim in itself but also a mean for the economic development. The present article highlights the negative relationship between gender inequality and development. It points out the existence of gender inequality traps associated with low economic performances. Moreover, it insists on the role of cultural norms on the persistence of such traps.

The model is also capable to replicate some stylized facts concerning the pattern of development of West Europe and United States. The process of economic development comes with a U-shaped evolution of the women labor supply and the progressive decreases of the educational gender gap. In line with the empirical evidences provided by Goldin (1995), the present model highlights the role played by stigma against women in early stages of development on this pattern.

The present article also provides testable findings on the relationship between FDI and the evolution of the gender gap. It predicts that FDI flows targeted towards low-skill occupations would narrow the gender gap in both poor and rich countries, while FDI flows targeted towards high-skill 
occupations have a widening impact on the gender gap in poor countries and a narrowing impact in rich countries. This result directly comes from the fact that only men receive education in poor countries. This result is obviously restrictive. However, if the educationnal gender gap is high, an increase in the returns to education (due to FDI net inflows) may disproportionally benefit to men workers rather than women.

Finally, the model is in the line with a growing literature trying to relate religion to beliefs or values influencing economic growth. Putman (1993), La Porta et al. (1997) an Inglehart (1999) focus on the relationship between religion and the level of trust. Landes (1998) argues that the culture of intolerance diffused by Catholic Church impeded the development of Spain in the 16th and 17th century. Guiso et al. (2006) find evidence on the impact of religion on preferences for redistribution and, in turn, of such preferences on the amount of redistribution that occurs. According to the present article, the economic outcomes of a country can also be affected by religion through its impact on gender role attitudes. Since both the relationship between religion and views about gender role and the relationship between gender inequality and growth have been highlighted (see Guiso et al. (2003) for the first and Knowles et al. (2002) for the second), this channel seems relevant. However, it needs to be more deeply investigated. 


\section{References}

Albanesi, S., \& Olivetti, C. 2006. Home production, Market Production and the Gender Wage Gap: Incentives and Expectations. NBER Working Paper.

Albanesi, S., \& Olivetti, C. 2007. Gender Roles and Technological Progress. NBER Working Paper.

Alesina, A., \& Giuliano, P. 2007. The Power of the Family. NBER Working Paper.

Altonji, J.G., \& Blank, M. 1999. Race and Gender in the Labour Market. Pages 3143-3259 of: Handbook of Labor Economics. North Holland: Amsterdam.

Arrow, K. 1973. The Theory of Discrimination. Pages 3-33 of: Discrimination in Labor Markets. NJ: Princeton University Press.

Bisin, A., \& Verdier, T. 2001. The economics of cultural transmission and the dynamics of preferences. Journal of Economic Theory, 97(1), 298-319.

Blomquist, S.N. 1993. Interdependent Behavior and the Effect of Taxes. Journal of Public Economics, 51, 211-218.

Bonatti, L. 2008. Evolution of preferences and cross-country differences in time devoted to market work. Labour Economics. doi:10.1016/j.labeco.2007.12.005.

Cagatay, N., \& S., Ozler. 1995. Feminization of the Labor Force: The Effects of Long-Term Development and Structural Adjustment. World Development, 23, 1183-1894.

Davison, J., \& Kanyuka, M. 1992. Girls' Participation in Basic Education in Southern Malawi. Comparative Education review, 36, 446-466.

De la Croix, D., \& Vander Donckt, M. 2008 (July). Would Empowering Women Initiate the Demographic Transition in Least-Developed Countries. CORE Discussion Paper. 
de la Rica, S., Dolado, J., \& Garcia-Peñalosa, C. 2008. On Gender Gap and Self-fulfilling Expectations: theory, Policies and some Empirical Evidences. CEPR Discussion Paper.

Dollar, D., \& Gatti, R. 1999. Gender Inequality, Income, and Growth: Are Good Times Good For Women. World Bank working paper.

Durand, J.D. 1975. The Labor Force in Economic Development and Demographic Transistion. Pages 47-78 of: Population Growth and Economic Development in the Third World. Dolhain, Belgium: Oridna Edition.

Escriche, L. 2007. Persistence of Occupational Segregation: The Role of Intergenerational Transmission of Preferences. The Economic Journal, 117, $837-857$.

Escriche, L., Olcina, G., \& Sanchez, R. 2004. Gender Discrimination and Intergenerational Transmission of Preferences. Oxford Economic Papers, 56, 485-511.

Faria, J.R., \& Leon-Ledesma, M.A. 2004. Habit Formation, Work Ethics and Technological Progress. Manchester School, 72, 403-413.

Farré, L., \& Vella, F. 2007. The Intergenerational Transmission of Gender Role Attitudes and its Implications for Female Labor Force Participation. IZA Discussion Paper No. 2802.

Fernandez, R. 2006. Culture and Economics. In: New Palgrave Dictionary of Economics. Palgrave Macmillan.

Fernandez, R. 2007. Women, Work and Culture. Journal of the European Economic Association, 5, 305-332.

Fernandez, R., \& Fogli, A. 2007. Culture: An Empirical Investigation of Beliefs, Work, and Fertility. NYU Working Paper.

Fernandez, R., Fogli, A., \& Olivetti, C. 2004. Mothers and Sons: Preference Formation and Female Labor Force Dynamics. Quarterly Journal of Economics, 119.

Galor, O., \& Weil, D. 1996. The Gender Gap, Fertility, and Growth. American Economic Review, 86, 374-387. 
Goldin, C. 1995. The U-shaped Female Labor Force Function In Economic Development and Economic History. In: Investment in Women's Human Capital. Chicago: University of Chicago Press.

Greenhalgh, S. 1985. Sexual Stratification: The Other Side of the 'Growth with Equity' in East Asia. Population and Development Review, 11, 265314.

Guiso, L., Sapienza, P., \& Zingales, L. 2003. People's Opium? Religion and Economic Attitudes. Journal of Monetary Economics, 50, 225-282.

Guiso, L., Sapienza, P., \& Zingales, L. 2006. Does Culture Affect Economic Outcomes? Journal of Economic Perspectives, 20, 23-48.

Hyde, K. 1993. Women's Education in Developing Countries: Barriers, Benefits and policies. World Bank. Chap. Sub-Saharan Africa, pages 100-135.

Inglehart, R. 1999. Trust, Well-being and Democraty. Pages 88-120 of: Democarty and Trust. Cambridge: Cambridge University Press.

Inglehart, R., \& Norris, P. 2003. Gender Equality and Cultural Change around the World. Cambridge: Cambridge University Press.

Jakee, K., \& Guang-Zhen, S. 2005. External Habit Formation and Dependency in the Welfare State. European Journal of Political Economy, 21, 83-98.

Kawaguchi, D., \& Miyazaki, J. 2008. Working Mothers and Sons' Preferences Regarding Female Labor Supply: Direct Evidence from Stated Preferences. Journal of Population Economics. DOI No. 10.1007/s00148-007-0175-2.

Klasen, S. 1999. Does Gender Inequality Reduce Growth and Development? Evidence from Cross-Country Regressions. World Bank working paper.

Knowles, S., Lorgelly, P., \& Owen, D. 2002. Are Educational Gender Gaps a Brake on Economic Development? Some Cross-Country Empirical Evidence. Oxford Economic Papers, 54, 118-149.

La Porta, R., Lopez-de Silanes, F., Schleifer, A., \& Vishny, R.W. 1997. Trust in Large Organizations. The American Economic Review, 87, 333-338. 
Lagerlöf, N-P. 2003. Gender Equality and Long-Run Growth. Journal of Economic Growth, 8, 403-426.

Landes, D. 1998. The Wealth and Poverty of Nations. London: Little, Brown, and Company.

Lindbeck, A. 1995. Welfare State Disincentives with Endogenous Habits and Norms. Scandinavian Journal of Economics, 97, 477-494.

Lindbeck, A., Nyberg, S., \& Weibull, J.W. 1999. Social Norms and Economic Incentives in the Welfare State. The Quarterly Journal of Economics, 114, $1-35$.

Mammen, K., \& Paxson, C. 2000. Women's Work and Economic Development. Journal of Economic Perspective, 14, 141-164.

McCleary, R.M., \& Barro, R.J. 2006. Religion and Economy. Journal of Economic Perspectives, 20, 49-72.

Moav, O. 2005. Cheap Children and the Persistence of Poverty. The Economic Journal, 115, 88-110.

Oostendorp, R. 2004. Globalization and the Gender Wage Gap. World Bank Policy Research Working Paper.

Phelps, E. 1972. The Statistical Discrimination of Racism and Sexism. The American Economic Review, 62, 659-661.

Putman, R. 1993. Making Democraty Work. Civic Tradition in Modern Italy. Princeton: Princeton University Press.

Rosenzweig, M.R., \& Schultz, T.P. 1982. Market Opportunities, Genetic Endowments, and Intrafamily Resource Distribution: Child Survival in Rural India. The American Economic Review, 72, 803-815.

Strulik, H. 2003. Economic Growth and Stagnation with Endogenous Health and Fertility. Journal of Population Economics, 17, 433-453.

Vella, F. 1994. Gender Roles and Human Capital Investment: The Relationship between Traditional Attitudes and Female Labour Market Performance. Economica, 61, 191-211. 
Woittiez, I., \& Kapteyn, A. 1998. Social Interactions and Habit Formation in a Model of Female Labour Supply. Journal of Public Economics, 70, 185-205.

World Development Report, WDR. 2006. Equity and Development. World Bank.

Zick, C.D., Bryant, W.K., \& Srisukhumbowornchai, K. 2008. Does Housework Matter Anymore? The Shifting Impact of Housework on Economic Inequality. Review of Economics of the Household, 6, 1-28. 


\section{Appendices}

\section{A Analysis of the $h h$ locus}

\section{Poverty regime}

If $h_{t}<\tilde{h}(1)$, neither boys nor girls are educated, then $h_{t+1}=h_{t}=2 c$ (see Section 4.5). As a consequence, the $h h$ locus consists in the horizontal line: $h=2 c$. Notice that, if $2 c>\tilde{h}(1)$, this locus of stationarity is outside of the poverty regime, then the economy always escape from this regime.

\section{Gender inequality regime}

In that case, the set of values of $h_{t}$ such that $\Delta h_{t}=0$ is denoted $h_{g i}^{h h}$ From (21) this locus of stationarity of $h_{t}$ is:

$$
h_{g i}^{h h}=\frac{c+\chi(0)(a b+\tau c)}{1-a \chi(0)}=\frac{\tau c(1+2 \beta)+a b \beta}{\tau+(\tau-a) \beta}
$$

Which is positive under condition (22). Hence, the $h h$ locus consists in the horizontal line such that $h=h_{g i}^{h h}$.

\section{Interior regime}

In this regime, the set of values of $h_{t}$ such that $\Delta h_{t}=0$ is denoted $h_{i}^{h h}\left(\theta_{t}\right)$. From (21), this locus of stationarity is:

$$
h_{i}^{h h}\left(\theta_{t}\right)=\frac{\chi\left(\theta_{t}\right)\left(1+\theta_{t}\right)(a b+2 \tau c)}{1-a \chi\left(\theta_{t}\right)\left(1+\theta_{t}\right)}=\frac{\beta\left(1+\theta_{t}\right)(a b+2 \tau)}{\tau+(\tau-a) \beta\left(1+\theta_{t}\right)}
$$

Which is positive under condition (22) and is increasing and concave in $\theta_{t}$. Then, in the plan $\left(h_{t}, \theta_{t}\right)$, the $h h$ locus in the case of the interior regime consists in an increasing and concave function denoted $h_{i}^{h h}\left(\theta_{t}\right)$.

Moreover, it is straightforward that the solution of the equation $h_{g i}^{h h}=$ $\tilde{h}\left(\theta_{t}\right)$ is the same than the solution of the equation $h_{i}^{h h}=\tilde{h}\left(\theta_{t}\right)$, that is:

$$
\theta_{t}=\frac{[(1+\beta) \tau-a \beta] c}{\beta[a(c+b)+\tau c]}
$$




\section{B Analysis of the $\theta \theta$ locus}

\section{Poverty regime}

In this regime, neither men nor women are educated. However, men display a higher productivity since they are endowed with physical strength. From (20a), (20b) and (25), the evolution of $\theta_{t}$ is given by:

$$
\Delta \theta_{t}=\theta_{t+1}-\theta_{t}=(1-\sigma)\left[(1-\lambda)\left(\frac{c}{c+b}\right)^{\frac{\kappa}{1-\gamma}}-\theta_{t}\right]
$$

Then, in the plan $\left(h_{t}, \theta_{t}\right)$, the $\theta \theta$ locus consists in the vertical line of equation $\theta=(1-\lambda)[c /(c+b)]^{\kappa /(1-\gamma)}<1$.

\section{Gender inequality regime}

From (20a), (20b) and (25), the evolution of $\theta_{t}$ in this regime is given by:

$$
\Delta \theta_{t}=(1-\sigma)\left[(1-\lambda)\left(\frac{c}{\chi(0)\left[a\left(h_{t}+b\right)+\tau c\right]+b}\right)^{\frac{\kappa}{1-\gamma}}-\theta_{t}\right]
$$

In that case, the set of values of $h_{t}$ such that $\Delta \theta_{t}=0$ is denoted $h_{g i}^{\theta \theta}\left(\theta_{t}\right)$. From (35), this locus of stationarity of $\theta_{t}$ is:

$$
h_{g i}^{\theta \theta}\left(\theta_{t}\right)=\frac{\tau c(1+\beta)(1-\lambda)^{\frac{1-\gamma}{\kappa}}}{a \beta \theta_{t}^{\frac{1-\gamma}{\kappa}}}-\frac{\beta(\tau c+a b)+\tau b(1+\beta)}{a \beta}
$$

It is a decreasing and a convex function of $\theta_{t}$, with $h_{g i}^{\theta \theta}\left((1-\lambda)[c /(c+b)]^{\kappa /(1-\gamma)}\right)=$ $\tilde{h}(1)$ and $\lim _{\theta_{t} \rightarrow 0} h_{g i}^{\theta \theta}\left(\theta_{t}\right)=+\infty$.

By (35), the level of $\theta_{t}$ at the point of intersection between $\tilde{h}\left(\theta_{t}\right)$ and $h_{c}^{\theta \theta}\left(\theta_{t}\right)$ is given by the equation:

$$
\theta_{t}=(1-\lambda)\left(\frac{c}{\chi(0)\left[a\left(\tilde{h}\left(\theta_{t}\right)+b\right)+\tau c\right]+b}\right)^{\frac{\kappa}{1-\gamma}}=(1-\lambda)\left(\frac{c \theta_{t}}{c+b \theta_{t}}\right)^{\frac{\kappa}{1-\gamma}} \equiv m\left(\theta_{t}\right)
$$

with $m(0)=0, m(1)=(1-\lambda)[c /(c+b)]^{\frac{\kappa}{1-\gamma}} \in(0,1), m^{\prime}\left(\theta_{t}\right)>0$ and $m^{\prime \prime}\left(\theta_{t}\right)<0$. Then a unique value of $\theta_{t} \in(0,1)$ is solution of the equation (37). It follows that $h_{c}^{\theta \theta}\left(\theta_{t}\right)$ crosses $\tilde{h}\left(\theta_{t}\right)$ only once. 


\section{Interior regime}

In the case of an interior solution on educational choices $\left(h_{t}>\tilde{h}\left(\theta_{t}\right)\right)$, the equation of evolution of $\theta_{t}$ can be rewritten as:

$$
\Delta \theta_{t}=(1-\sigma)\left[(1-\lambda)\left(\frac{\chi\left(\theta_{t}\right) \theta_{t}\left[a\left(h_{t}+b\right)+2 \tau c\right]}{\chi\left(\theta_{t}\right)\left[a\left(h_{t}+b\right)+2 \tau c\right]+b}\right)^{\frac{\kappa}{1-\gamma}}-\theta_{t}\right]
$$

The set of values of $h_{t}$ such that $\Delta \theta_{t}=0$ is denoted $h_{i}^{\theta \theta}\left(\theta_{t}\right)$. From (38), this locus of stationarity of $\theta_{t}$ is:

$$
h_{i}^{\theta \theta}\left(\theta_{t}\right)=\frac{b \theta_{t}^{\frac{1-\gamma}{\kappa}}}{a \chi\left(\theta_{t}\right)\left((1-\lambda)^{\frac{1-\gamma}{\kappa}} \theta_{t}-\theta_{t}^{\frac{1-\gamma}{\kappa}}\right)}-\frac{a b+2 \tau c}{a}
$$

Under condition (27), $h_{i}^{\theta \theta}\left(\theta_{t}\right)$ is an increasing of $\theta_{t}$ with $\lim _{\theta_{t} \rightarrow 1} h_{i}^{\theta \theta}\left(\theta_{t}\right)=+\infty$.

By (38), the level of $\theta_{t}$ at the point of intersection between $\tilde{h}\left(\theta_{t}\right)$ and $h_{g i}^{\theta \theta}\left(\theta_{t}\right)$ is given by the equation:

$$
\theta_{t}=(1-\lambda)\left(\frac{\chi\left(\theta_{t}\right) \theta_{t}\left[a\left(\tilde{h}\left(\theta_{t}\right)+b\right)+2 \tau c\right]}{\chi\left(\theta_{t}\right)\left[a\left(\tilde{h}\left(\theta_{t}\right)+b\right)+2 \tau c\right]+b}\right)^{\frac{\kappa}{1-\gamma}}=(1-\lambda)\left(\frac{c \theta_{t}}{c+b \theta_{t}}\right)^{\frac{\kappa}{1-\gamma}}
$$

It results that $h_{g i}^{\theta \theta}\left(\theta_{t}\right)$ and $h_{g i}^{\theta \theta}\left(\theta_{t}\right) \operatorname{cross} \tilde{h}\left(\theta_{t}\right)$ at the same point.

\section{Proof of Proposition 1}

It follows from (34), (35) and (38) that the $\theta \theta$ locus is stable. Then, $\Delta \theta_{t}$ is positive (negative) if the economy is at the left (at the right) ot the $\theta \theta$ locus. In the same way, it follows from (21) that the $h h$ locus is stable. It results:

$$
\Delta h_{t}\left\{\begin{array}{lll}
>0 & \text { if } \quad h_{t}<2 c \\
=0 & \text { if } \quad h_{t}=2 c \\
<0 & \text { if } \quad h_{t} \in(2 c, \tilde{h}(1)) \\
>0 & \text { if } \quad h_{t} \in\left[\tilde{h}(1), \max \left\{h_{g i}^{h h}, h_{i}^{h h}\left(\theta_{t}\right)\right\}\right) \\
=0 & \text { if } \quad h_{t}=\max \left\{h_{g i}^{h h}, h_{i}^{h h}\left(\theta_{t}\right)\right\} \\
<0 & \text { if } \quad h_{t}>\max \left\{h_{g i}^{h h}, h_{i}^{h h}\left(\theta_{t}\right)\right\}
\end{array}\right.
$$

If $2 c \leq \tilde{h}(1)$, the $\theta \theta$ locus and the $h h$ locus crosses in the poverty regime. It results in one stable equilibrium in this regime, i.e. for all values of $h_{t}$ lower 
than $\tilde{h}(1)$ the economy converges towards this equilibrium. Conversely, if $2 c>\tilde{h}(1)$, the $\theta \theta$ locus and the $h h$ locus do not cross in the poverty regime. For all values of $h_{t}$ lower than $\tilde{h}(1), \Delta h_{t}>0$, then the economy escapes from the poverty regime.

Finally, It follows from the representation of the two loci (Figure 2 and 3 ), that the $h h$ locus and the $\theta \theta$ locus crosses at least once and at most three outside of the poverty regime. 